\title{
Pedagogía de la enseñanza teológica. La condescendencia de Dios como clave hermenéutica fundamental para la enseñanza teológica
}

\author{
Joaquin Silva Soler \\ FACULTAD DE TEOLOGÍA \\ PONTIFICIA UNIVERSIDAD CATÓLICA DE CHILE
}

\section{Introducción}

El título de esta presentación supone dos cuestiones fundamentales: que hay una enseñanza teológica y que hay una pedagogía de la enseñanza teológica.

Lo primero parece ser un hecho indesmentible: enseñamos teología. Lo segundo, sin embargo, nos plantea una interrogante: ¿cuál es la pedagogía que anima nuestra enseñanza teológica? El hecho nos cuestiona. Dicho de otro modo, nuestra propia enseñanza teológica nos resulta cuestionable. Ella no es evidente por sí misma; nos preguntamos por sus condiciones y posibilidades; requerimos establecer bajo qué supuestos teóricos y prácticos aquel hecho es viable. Así, entonces, surge una pregunta del todo inquietante: quizás, no estamos siendo sujetos de una enseñanza teológica. El hecho que parecía indesmentible -que hay una enseñanza teológica- ahora, cuando preguntamos por sus condiciones y posibilidades pedagógicas, también se vuelve objeto de duda.

La mirada pedagógica, por tanto, no debe ser considerada como una cuestión extrínseca a la enseñanza teológica, puesto que ella nos ayuda a revisar críticamente nuestras prácticas de enseñanzas y, así, a determinar si lo que hacemos es -efectivamente-enseñar. Pero, la mirada crítica de la pedagogía no sólo pregunta críticamente sobre la calidad del proceso mismo de enseñanza, sino que esta misma pregunta la lleva a indagar -según su propio objeto formal- por la calidad teológica de ese proceso de enseñanza. ¿Cómo es esto posible?

Para el proceso pedagógico no es indiferente el hecho de que la enseñanza sea teológica. La pedagogía establece las reglas propias de su pro- 
ducción no en abstracto, sino que en función de destinatarios, objetivos y contenidos específicos. Por cierto, la pedagogía no está en condiciones de pronunciarse respecto de la calidad de determinados contenidos teológicos: si éstos se han asegurado suficientemente -de acuerdo a las condiciones epistemológicas propias del quehacer teológico-, si ellos efectivamente corresponden a la Revelación de Dios en Cristo. Este tipo de cuestiones sólo pueden ser resueltas al interior mismo de la práctica teológica. Sin embargo, la pedagogía puede llegar a establecer si el proceso de enseñanza efectivamente es coherente, o no, con las cuestiones teológicas respecto de las cuales se constituye. De este modo, la pedagogía puede ayudar a identificar los modos de enseñanza y aprendizaje que mejor se adecuen a las materias y cuestiones teológicas de las que se trata. No será lo mismo enseñar Trinidad que teología moral, por ejemplo. En el primer caso, la pedagogía recomendará prácticas de enseñanza y de aprendizaje que ayuden a los estudiantes a reconocer la pregunta por Dios en los diferentes contextos culturales en que ella se plantea, que favorezcan el análisis y comprensión de fuentes, que fomenten la reflexión especulativa, etc. En el segundo caso, cuando se trata de cuestiones morales, probablemente la enseñanza y aprendizaje tendrán un componente interdisciplinar más acentuado, se indagará sobre principios, supuestos y condicionamientos del comportamiento ético, se privilegiará la resolución de preguntas éticas concretas, etc. En uno y otro caso se trata de procesos de enseñanza teológica; sin embargo, los desafíos pedagógicos no coinciden plenamente, cada uno de ellos tiene particularidades que lo diferencia.

Lo anterior nos está indicando, entonces, que los desafíos pedagógicos en teología -siendo en muchos casos comunes a cualquier práctica de enseñanza y aprendizaje- están condicionados por la naturaleza misma de la teología. Así como la pedagogía puede ayudar a esclarecer la pertinencia de algunos contenidos teológicos -en razón de tiempos, lugares, personas-, la teología también puede llegar a determinar la pertinencia de determinadas prácticas pedagógicas. La relación pedagogía-teología no se determina unidireccionalmente, sino que se resuelve por una relación que, siendo crítica, es de reciprocidad, de mutuo intercambio, de inclusión. En efecto, la enseñanza de la teología no se deja determinar -simplemente- por los hallazgos de las ciencias de la educación. Éstos, por cierto, le ayudarán a revisar críticamente sus propias prácticas pedagógicas; sin embargo, no son esos hallazgos los que tienen la última palabra. La enseñanza teológica deberá incorporar en su quehacer los avances de la peda- 
gogía; pero, a su vez, éstos se deberán adecuar al objeto propio sobre el cual versa esta enseñanza. Es la teología, y la comprensión que de ella se tenga, la que determina cuáles son los procesos de enseñanza y aprendizaje más consecuentes con su propia naturaleza.

Un camino posible para abordar la relación entre pedagogía y teología sería el de preguntar a la primera -a la pedagogía- por las exigencias que ella impone a la teología, a fin de que la enseñanza de esta disciplina sea efectivamente consistente con los resultados que se esperan. En esta perspectiva habría que resolver, principalmente, las dos cuestiones siguientes: una general, la definición de la malla curricular; y otra más específica, la planificación de los procesos de enseñanza y aprendizaje de cada asignatura. Se trata este de un camino posible, pero requiere ser propuesto por alguien que en cuestiones pedagógicas sea más competente que nosotros.

Mi propuesta es entrar al tema de la enseñanza teológica por la teología misma; es decir, quisiera aquí plantear los desafíos pedagógicos que plantea la misma enseñanza de la teología. No se trata de escabullir la pregunta pedagógica, sino de asumirla desde aquello que la determina internamente, desde aquello la hace ser, propiamente, enseñanza teológica. Pensamos que, de este modo, no estaremos estableciendo un hiato insalvable entre pedagogía y teología, sino que nos estaremos preguntando por la unidad que hace posible el que ambas -en su diferencia- se reconozcan en su mutua relación, en aquel único proceso que es la enseñanza teológica.

Por cierto, hay diversas perspectivas teológicas que nos podrían servir para abordar pertinentemente nuestra práctica pedagógica. Elegir una u otra perspectiva, al menos en parte, dependerá de los acentos que queramos poner: si queremos destacar cuestiones de orden pedagógico, podría ser útil, p.e., analizar cómo Jesús enseñaba a través de parábolas; si, en cambio, quisiéramos concentrar nuestra mirada en cuestiones más de orden teológico, entonces podríamos atender más directamente a las enseñanzas sobre Dios que nos transmiten los hechos y palabras de Jesús; o, por último, si nuestro interés consiste en mostrar la estrecha relación que existe entre lo pedagógico y lo teológico, en este caso, por ejemplo, sería aconsejable tratar del kerigma, para reconocer allí el misterio de Dios en cuanto comprendido, acogido y proclamado. Estas entradas teológicas son todas plausibles y, además, se complementan unas a otras. 
Sin embargo, en lugar de seguir algunos de estos caminos, nos hemos preguntado por la posibilidad de encontrar algún hecho teológico mayor, que nos sirva como clave hermenéutica fundamental para comprender la relación entre pedagogía y teología. Cuando nos hicimos esta pregunta, se nos ocurrieron distintos conceptos que, con justo derecho, reclamaban ser parte de la respuesta: salvación, perdón, amor, solidaridad, esperanza, revelación, conversión, ... Todos ellos eran posibles y con infinitas potencialidades de desarrollo. Pero, de pronto, pensando en aquellos rasgos característicos de la acción de Dios en Cristo, ha emergido a nuestra conciencia un concepto teológico que queremos proponer como clave hermenéutica fundamental para la enseñanza teológica. Se trata del concepto de condescendencia y que, a continuación, queremos explicar brevemente.

La condescendencia de Dios como clave hermenéutica fundamental para la enseñanza teológica

La explicación del concepto de condescendencia no es una tarea fácil. Contrariamente a lo que pensábamos, se trata de un concepto escasamente desarrollado en la teología. Y, por lo mismo, tampoco es un concepto incluido en los principales Diccionarios y Manuales de teología. ¿Entonces? Entonces decidimos indagar sobre el significado del concepto a partir de la referencia textual más inmediata y, a partir, de allí proponer una comprensión teológico-fundamental que sirviera para nuestros propósitos de mirar críticamente la enseñanza teológica.

La referencia textual más inmediata la constituye el número 13 de Dei Verbum. Con este texto se concluye el capítulo III, dedicado a la importante cuestión de la inspiración e interpretación de la Sagrada Escritura ${ }^{1}$. Dice así:

«Sin mengua de la verdad y de la santidad de Dios, la Sagrada Escritura nos muestra la admirable condescendencia [condescensio] de la Sabiduría eterna, "para que aprendamos su amor inefable y cómo adapta [attemperatione] su lenguaje a nuestra naturaleza con providencia solícita". La palabra de Dios, expresada en lenguas humanas, se hace semejante [assimilia] al lenguaje humano, como la Palabra del Padre eterno, asumiendo la carne de la debilidad humana, se hizo semejante a los hombres» [DH 4220].

1 Para un comentario a este número, véase: H. Hoping, «Theologischer Kommentar zur Dogmatischen Konstitution über die göttliche Offenbarung: Dei Verbum», en: Herders theologischer Kommentar zum Zweiten Vatikanischen Konzil, vol. 3, Herder, Freiburg im Breisgau 2005, 775-776. 
Según este texto, que desarrolla la idea de Dei Verbum 2, la condescendencia de la Sabiduría eterna se verifica tanto en un nivel lingüístico-comunicativo, como en un nivel ontológico. Según el primer nivel, la condescendencia consiste en la adaptación [attemperatione] del lenguaje de Dios a nuestro lenguaje humano. Y, en un segundo nivel, en el nivel ontológico, el texto afirma que la condescendencia de Dios consiste en el hecho mismo de la Encarnación: es la Palabra del Padre que se hizo semejante a los hombres. Recurriendo a la analogía [sicut] del Verbo encarnado, la Dei Verbum refiere el nivel lingüístico al ontológico: así como la Palabra se hizo semejante a los hombres [simile factum], así la palabra de Dios se hizo semejante [assimilia] al lenguaje humano. Para expresar esta condescendencia de Dios, tanto en el nivel lingüístico como ontológico, el Concilio -al igual que lo había hecho la Encíclica Divino afflante Spiritu (Pío XII, 1943) - cita a San Juan Crisóstomo, quien habla de una synkatábasis de Dios en su Palabra hecha carne ${ }^{2}$.

Me parece importante distinguir estos dos niveles y, a la vez, reconocer la unidad que se establece entre ellos por medio de la analogía. De lo contrario, el nivel lingüístico pudiera ser visto como en una mera objetividad externa al acontecimiento mismo de la salvación. En cambio, el Concilio nos invita a comprender esta primera semejanza en relación a una semejanza mayor: a la semejanza que Dios ha querido tener con el hombre desde la creación del mundo y que, en Cristo, ha llevado a su plenitud. En

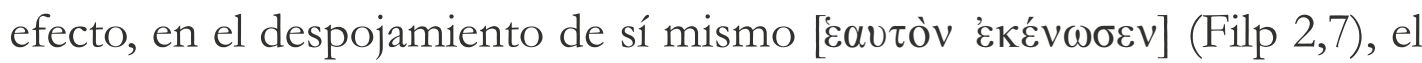
Dios trascendente se ha hecho Dios con nosotros (Mt 1,23), cumpliendo así las promesas hechas a su Pueblo (Is 7,14; 8,8), mostrándonos la radicalidad de su condescendencia.

Ahora bien, al remitirnos a esta semejanza mayor inmediatamente se nos hace patente la desemejanza. Por ello mismo el texto parte recordándonos que siempre debe ser salvada la verdad y santidad de Dios: salva semper Dei veritate et sanctitate. Sucede, sin embargo, que esta verdad y santidad no se salva en la distancia absoluta e inalcanzable de Dios, sino que,

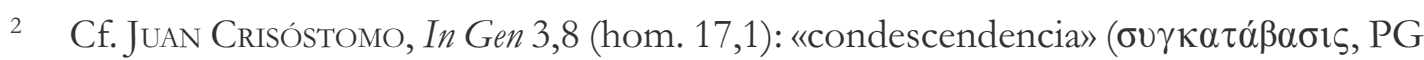
53,134). Según J. QuASTEN, «Crisóstomo desarrollo la doctrina de la condescendencia contra las interpretaciones equivocadas que dan los arrianos de las afirmaciones de Cristo acerca de su flaqueza humana, sobre su miedo y sufrimiento» (Patrología, v. II, BAC, Madrid 1994, 488). Véanse también Homilía VII, 253,269,484; Homilía X, 67,105,148,475 [en: Sources Chretiennnes, $\mathrm{n}^{\circ} 396$ ]. 
contrariamente a todo pronóstico, Él ha querido manifestar su divinidad en la kénosis de su Hijo, en nuestra propia humanidad.

Hasta aquí hemos destacado del texto sólo aquello que Dios hace y pareciera que los hombres y mujeres son meramente receptores de este actuar de Dios. Sin embargo, ello es -efectivamente- sólo apariencia. Este breve número conclusivo del Capítulo III debe ser interpretado a la luz de aquello que Dei Verbum definió como De ipsa revelatione. Según el Concilio, Dios quiso revelarse a sí mismo y su voluntad, para que «por Cristo, la Palabra hecha carne, y con el Espíritu Santo, puedan los hombres llegar hasta el Padre y participar de la naturaleza divina» [DH 4202]. De este modo, la condescendencia de Dios posibilita nuestra participación en la vida trinitaria; ella está movida por el amor -como también afirma nuestro $n^{\circ}$ 13-, pero, a su vez, es invitación a participar en la vida divina; ella es expresión histórica de la cercanía siempre trascendente y amorosa de Dios: «... Dios invisible (cf. Col 1,15; 1 Tim 1,17), movido de amor, habla a los hombres como amigos (cf. Ex 33,11; Jn 15,14-15), trata con ellos (cf. Bar $3,38)$ para invitarlos y recibirlos en su compañía».

La condescendencia de Dios no es así una mera estrategia comunicativa, sino que ella misma es acontecimiento de salvación. Dios nos quiere hacer partícipes de su «amor inefable», y por ello nos habla como a amigos. Este hablar de Dios, por su parte, se realiza de modo pleno y definiti-

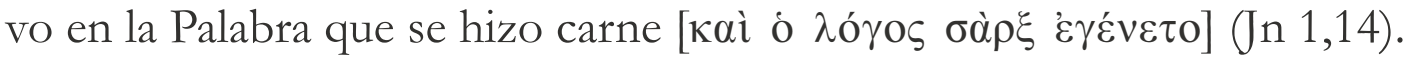

¿Y qué tiene que ver todo esto con la enseñanza teológica y con la pedagogía de la enseñanza teológica?

A nuestro entender, cuando nos preguntamos por la pedagogía de la enseñanza teológica, y lo queremos hacer teológicamente, entonces la categoría de condescendencia de Dios nos ofrece una perspectiva teológicofundamental que es preciso explicitar.

\section{La enseñanza teológica en la lógica de la condescendencia}

La condescendencia de Dios nos remite al núcleo o esencia del quehacer teológico. Si entendemos la teología como un lógos acerca de Dios, entonces éste, nuestro lógos, no puede sino estar fundado en el Lógos de Dios. Según vimos, es la Palabra hecha carne la que funda toda posible semejanza de la palabra humana con la palabra de Dios. Al lenguaje humano se le ha regalado la posibilidad de expresar históricamente el querer salvífico de 
Dios. La enseñanza de la teología, por tanto, será enseñar a reconocer a ese Dios que desde la creación se ha querido hacer semejante a los hombres y que, en su Hijo Jesús, la Palabra que se hizo carne, hace posible toda palabra sobre Dios.

Por la «admirable condescendencia de la Sabiduría eterna» nos ha sido posible llegar a alguna inteligencia del misterio de Dios. Aún vemos veladamente y no conocemos plenamente (cf. 1 Cor 13,12); sin embargo, la palabra de Dios se ha querido hacer semejante a la nuestra, para que desde ahora $\left[\dot{\alpha} \pi^{\circ} \alpha \ddot{\alpha} \rho \tau\right]$, en Jesús, podamos ver y reconocer al Padre (cf. Jn 14,7). Toda enseñanza teológica, por tanto, tiene como referencia fundamental esta admirable condescendencia, la que será siempre un salir de sí para ir en busca del otro.

Como expresión histórica de la condescendencia del Verbo eterno de Dios, la enseñanza teológica no se podrá contentar con una cierta coherencia interna en sus enunciados, sino que deberá descender allí donde realmente se encuentran los hombres y mujeres de cada tiempo y lugar. La enseñanza teológica queda así situada en el movimiento mayor que implica la evangelización de la cultura, de la inculturación del Evangelio. La misma preposición «con» nos está indicando que el necesario descenso de la enseñanza teológica no se hace por un movimiento ensimismado por parte del teólogo, sino que éste acontece al interior de una comunidad de vida y de fe que, animada por Espíritu, busca dar testimonio del Evangelio, en diálogo con los hombres y mujeres de cada tiempo.

Este con-descender significa, por tanto, un hacerse parte, un compartir aquella vida en la que puede tener sentido algo así como la «enseñanza de la teología». Un compartir que no es sólo hablar, sino que es también escuchar; así como también lo hizo quien se despojó de sí mismo para hacerse semejantes a nosotros, quien nos ha querido decir que sus casi treinta años de «vida oculta» son también expresión de su condescendencia. Pareciera que una auténtica relación pedagógica sólo surge cuando es posible compartir la cultura del otro, cuando se establecen códigos de muto entendimiento, cuando aquello que se enseña responde eficazmente a preguntas, problemas, cuestiones que son efectivamente relevantes para la vida de quienes están involucrados en el proceso pedagógico.

En esta perspectiva nos parecen plenamente atingentes las enseñanzas de uno de los últimos textos promulgados por el Concilio Vaticano II, el Decreto Ad gentes, sobre la actividad misionera de la Iglesia. En 
este documento encontramos un pasaje que, partiendo de la imagen de la semilla -que requiere de la tierra para germinar y dar fruto-, y de la analogía del plan de la Encarnación, explica cómo la Iglesia y la teología requieren de la cultura para la inteligencia de la fe, para expresar la gloria de Dios $^{3}$.

En este sentido del con-descender, el Papa Juan Pablo II nos recordó que Santa Teresa nos enseñaba que en Cristo es posible reconocer tanto la majestad de la divinidad como la condescendencia de su humanidad: «Es gran cosa mientras vivimos y somos humanos, traerle humano»; «veía que aunque era Dios, que era Hombre, que no se espanta de las flaquezas de los hombres ${ }^{4}$. En esta perspectiva, la con-descendencia del Hijo de Dios adquiere en Jesús de Nazaret una concreción que no es posible pasar por alto, a riesgo de negar aquello que ella misma quiere afirmar. Es así que San Pablo escribe a la Comunidad de Corinto: «Porque conocen la gracia de nuestro Señor Jesucristo, que siendo rico, sin embargo por amor a

3 «La semilla, que es la palabra de Dios, al germinar absorbe el jugo de la tierra buena, regada con el rocío celestial, y lo transforma y se lo asimila para dar al fin fruto abundante. Ciertamente, a semejanza del plan de la Encarnación, las iglesias jóvenes, radicadas en Cristo, y edificadas sobre el fundamento de los apóstoles, toman, en intercambio admirable, todas las riquezas de las naciones que han sido dadas a Cristo en herencia (cf. Sal 2, 8). Ellas reciben de las costumbres y tradiciones, de la sabiduría y doctrina, de las artes e instituciones de los pueblos todo lo que puede servir para expresar la gloria del Creador, para explicar la gracia del Salvador y para ordenar debidamente la vida cristiana. Para conseguir este propósito es necesario que en cada gran territorio socio-cultural se promueva la reflexión teológica por la que se sometan a nueva investigación, a la luz de la tradición de la Iglesia universal, los hechos y las palabras reveladas por Dios, consignadas en las Sagradas Escrituras y explicadas por los Padres y el Magisterio de la Iglesia. Así aparecerá más claramente por qué caminos puede llegar la fe a la inteligencia, teniendo en cuenta la filosofía y la sabiduría de los pueblos, y de qué forma pueden compaginarse las costumbres, el sentido de la vida y el orden social con las costumbres manifestadas por la divina revelación. Con ello se descubrirán los caminos para una acomodación más profunda en todo el ámbito de la vida cristiana. Con este modo de proceder se excluirá toda especie de sincretismo y de falso particularismo, se acomodará la vida cristiana a la índole y al carácter de cualquier cultura, y serán asumidas en la unidad católica las tradiciones particulares, con las cualidades propias de cada raza, ilustradas con la luz del Evangelio. Por fin, las iglesias particulares jóvenes, adornadas con sus tradiciones, tendrán su lugar en la comunión eclesiástica, permaneciendo íntegro el primado de la cátedra de Pedro, que preside a toda la asamblea de la caridad» (Concilio Vaticano II, Ad gentes 22).

4 Citada por Juan Pablo II, «Homilía en el IV Centenario de la muerte de Santa Teresa de Jesús» [1 de noviembre de 1982]. 
ustedes se hizo pobre, para que por medio de su pobreza ustedes llegaran a ser ricos» (2 Cor 8,9). Está a la mano la posibilidad de «espiritualizar» el sentido de esta afirmación. Sin embargo, el mismo Apóstol sale al paso de este intento: el ejemplo de Cristo, quien siendo rico se hizo pobre, se vuelve un imperativo para la práctica de la solidaridad con la comunidad de Jerusalén (2 Cor 8,7).

La condescendencia divina es tal, porque asume nuestra humanidad, nuestro lenguaje, nuestras condiciones espacio-temporales. Pero estas razones son aún muy generales y no dan cuenta de la radicalidad de la con-descendencia de Dios, que en Cristo se expresó como predilección hacia los pobres y pecadores, hacia cuantos son despojados de su dignidad y libertad. El lugar de los otros, en particular el lugar de los pobres, debiera determinar internamente la enseñanza teológica, si es que ésta efectivamente pretende ser cristiana. Si la enseñanza teológica no es capaz de ser efectivamente significativa para los predilectos de Dios, entonces ella corre el riesgo de volverse un discurso religioso más y que, muy probablemente, como discurso ideológico será sólo un remedo grotesco de aquella Palabra creadora de Dios que se hizo carne.

En esa misma homilía por el aniversario de Santa Teresa, el Papa Juan Pablo II reconocía en la que llama «condescendencia» de Jesús hacia la mujeres, una de la fuentes desde las que se había nutrido la libertad de Santa Teresa de Jesús: «iQué gozosa libertad interior le ha procurado, en tiempos de acentuado antifeminismo, esta actitud condescendiente del Maestro con la Magdalena, con Marta y María de Betania, con la Cananea y la Samaritana, esas figuras femeninas que tantas veces recuerda la Santa en sus escritos! No cabe duda que Teresa ha podido defender la dignidad de la mujer y sus posibilidades de un servicio apropiado en la Iglesia desde esta perspectiva evangélica: "No aborrecisteis, Señor de mi alma, cuando andabais por el mundo, las mujeres, antes las favorecisteis siempre con mucha piedad..." $\rangle^{5}$.

La condescendencia, de nuevo acá, no un «recurso pedagógico» sino que auténtica experiencia de libertad. Es decir, la condescendencia de Dios en Cristo no es un medio en función de otra cosa, sino que en ella misma acontece la cercanía de Dios al hombre y la mujer, su invitación a 5 Juan Pablo II, «Homilía en el IV Centenario de la muerte de Santa Teresa de Jesús»
$\left[1^{\circ}\right.$ de Noviembre de 1982]. 
entablar una relación de diálogo y amor con él. La misma libertad con que Jesús trata a las mujeres es fuente de vida y amor.

El desafío pedagógico que de aquí emana nos parece evidente: ¿cómo la enseñanza teológica es fuente de libertad?, ¿cómo los procesos de enseñanza y aprendizaje de la teología no ocultan, sino que ponen de manifiesta esta cercanía de Dios a los pobres, a los marginados, a los pecadores?, ¿cómo la enseñanza de la teología despierta esa ansia de libertad y liberación que Dios ha inscrito en lo más profundo del ser humano?

\section{La enseñanza teológica como expresión del amor de Dios}

La condescendencia de Dios, asociada como hemos visto al concepto de kénosis, nos sugiere un hecho pedagógico mayor: toda enseñanza teológica debe ser expresión histórica del amor con que Dios nos ha amado en su Hijo Jesús y nos sigue amando por el don de su Espíritu. La kénosis de la que habla Pablo en la carta a los Filipenses no es un discurso abstracto y desinteresado sobre el despojamiento del Hijo de Dios, sino que es una propuesta respecto del sentido último del actuar de la comunidad: «Tened

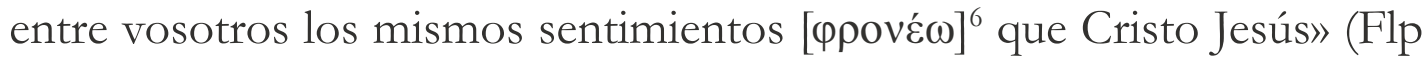
2,5). «Si Dios así nos amó -escribe Juan-, también nosotros debemos amarnos unos a otros» (1 Jn 4,11). La enseñanza de la teología no puede sino que estar internamente determinada por este acontecimiento de amor y donación del que ella nace, en el cual ella se sostiene, desde donde ella alcanza inteligencia [ $\varphi \rho o ́ v \varepsilon \sigma ı \varsigma]$ (cf. Hech 17,28: «Porque en Él vivimos, nos movemos y existimos...»).

La condescendencia no acontece, entonces, sólo para mediar una serie de contenidos y nociones necesarias para la salvación. Tanto ayer como hoy, esa voluntad salvífica de Dios es ya conocida: «la ley y los profetas». Más bien, Dios se despojó de sí mismo para hacerse nuestro amigo. Mientras ello no se entienda, se entiende muy poco. En su diálogo con el joven rico pareciera que Jesús, justamente, desvía la pregunta por el «qué» hacia el «quién», hacia una práctica consecuente con la bondad del Dios que ha salido a nuestro encuentro: «Jesús le respondió: “¿Por qué me

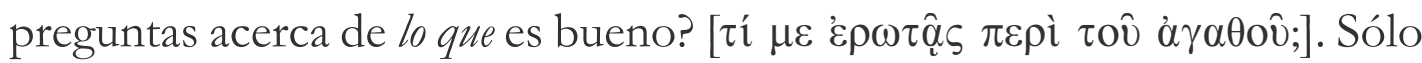
Uno es bueno; pero si deseas entrar en la vida, guarda los mandamientos"»

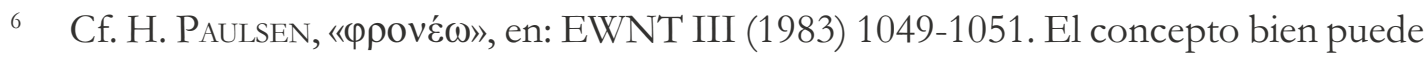
ser traducido por «pensar», «reflexionar», «aspirar a algo». 
(Mt 19,17). Dios, en Cristo, efectivamente nos ha querido enseñar qué es la bondad; pero ello no a través de un concepto claro y distinto -al final, siempre sujeto a nuestros intentos de dominio y poder- sino que a través de una presencia interpelante, de una presencia amorosa y liberadora, a través de su cercanía trascendente.

La teología no es sólo informativa, sino que performativa. Es urgente tomar conciencia de ello, ha dicho el papa Benedicto XVI: «Es el momento de preguntarnos ahora de manera explícita: la fe cristiana ¿es también para nosotros ahora una esperanza que transforma y sostiene nuestra vida? ¿Es para nosotros "performativa", un mensaje que plasma de modo nuevo la vida misma, o es ya sólo “información” que, mientras tanto, hemos dejado arrinconada y nos parece superada por informaciones más recientes?»》 ${ }^{7}$

En la enseñanza de la teología no se trata, simplemente, de informar respecto de determinados contenidos, sino que de remitir al acontecimiento de la autocomunicación de Dios en Cristo. ¿Cómo estamos detrás de aquello que enseñamos? ¿Cómo está nuestra vida personal, social, comunitaria, eclesial? ¿O, simplemente, como hijos de nuestro tiempo, vivimos una suerte de esquizofrenia entre fe y vida?

Pero hay otra dimensión de este proceso dialógico, quizás más honda, y que no se expresa sólo en categorías de preguntas y respuestas, sino que responde más fundamentalmente a esta estructura condescendiente de la revelación de Dios en Cristo. Nos referimos a dos textos paradigmáticos del Nuevo Testamento: Mt 21,1-16 y Lc 10,21.

El primero, en el contexto de la entrada de Jesús a Jerusalén, de la expulsión de los mercaderes del Templo, y de curaciones, es decir, en un contexto de manifestación mesiánica, Lucas nos cuenta que los niños «gritaban en el templo y decían: “¡Hosanna al Hijo de David!"». Los sacerdotes y escribas se indignaron por ello; y Jesús respondió a esta indignación con el salmista que decía: «De la boca de los pequeños y de los niños de pecho te has preparado alabanza» $(\operatorname{Lc} 21,16)$.

Y en el otro texto, en el de Lc 10,21, leemos la siguiente confesión solemne de Jesús: «... Jesús se regocijó mucho en el Espíritu Santo

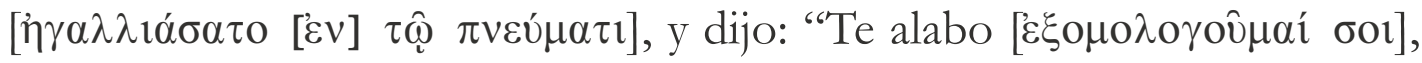
Padre, Señor del cielo y de la tierra, porque ocultaste estas cosas a sabios

Benedicto XVI, Spes salvi, 10. 
y a inteligentes, y las revelaste a niños. Sí, Padre, porque así fue de Tu agrado"».

No es el caso entrar a un análisis detallado de estos textos, pero, a nuestro entender, ellos expresan claramente cómo la condescendencia de Dios, su comunicación y don a la humanidad, no acontece en intrincadas disquisiciones formales o por la vías del poder, sino que se manifiesta en los niños, en los pequeños, en los pobres.... ¿Y por qué ello es así? La respuesta la encontramos en la misma confesión y alabanza de Jesús: por

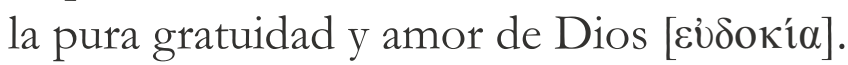

La teología, por más lúcida e inteligente que ella sea, es incapaz de producir este acontecimiento de la gratuidad y del amor de Dios, que se ha revelado de modo privilegiado a los pequeños y sencillos. Sin embargo, este hecho -en sí mismo- no hace a la teología irrelevante. Si ella se vuelve insignificante, entonces es porque ella se ha vuelto en contra de su propio objeto, porque ya no remite a la cercanía trascendente y liberadora de Dios, porque ya no es un testimonio lúcido -entre otros- del amor gratuito e incondicionado de Dios. Como afirma san Juan Crisóstomo, la condescendencia de Cristo «no resulta de la inferioridad de su condición», sino que es expresión de su humildad y amor, de su voluntad de escuchado y comprendido por quienes lo oían ${ }^{8}$.

\section{La enseñanza teológica remite al misterio de Dios}

El concepto de condescendencia de Dios -según dijimos- remite a un nivel lingüístico, pero, especialmente, a un nivel ontológico. Esto nos parece importante, puesto que la enseñanza de la teología no se reduce a una serie de prácticas pedagógicas asequibles, comprensibles, asimilables. Por cierto, esto no se niega. Sin embargo, el potencial del lenguaje teológico -según la analogía del Verbo encarnado- está en su capacidad de referir a Dios. En el sentido de la misma condescendencia como kénosis, esta no concluye en la encarnación, ni representa un movimiento puramente descendente. Más bien, la kénosis es un despojamiento indisolublemente asociado a un movimiento ascendente, de exaltación y de gloria (cf.Flp 2, 9-11). Guardando las distancias debidas, consideramos que todo proceso de enseñanza teológica debe expresar este dinamismo en el que según

8 Cf. Juan Crisóstomo, Homilía VII, 268-270. 
Tomás, «El acto (de fe) del creyente no se detiene en el enunciado, sino en la realidad (enunciada)»?

El con-descender kenótico de Dios hasta la cruz, como lo había ya entendido san Juan Crisóstomo, no pone en peligro la naturaleza de Dios, sino que enaltece la de hombre: «Se hizo Hijo del hombre el que era Hijo natural de Dios, para hacer hijos de Dios a los hijos de los hombres. Cuando el sublime se asocia con el humilde, no sufre para nada en su honor propio; en cambio, a éste le levanta de su gran bajeza. Lo mismo ocurrió con el Señor. No sufrió merma en su propia naturaleza por esta condescendencia; en cambio, a nosotros, que siempre estábamos sentados en desgracia y oscuridad, nos levantó a una gloria inefable» ${ }^{10}$.

Por este motivo, en la condescendencia divina Dios revela al hombre la plenitud de su propia humanidad, según enseñó certeramente Juan Pablo II en su importante encíclica sobre el Espíritu Santo en la Vida de la Iglesia y del Mundo. Leemos allí: «... el hombre, descubriendo en sí mismo su pertenencia a Cristo, y en a la elevación a "hijo de Dios", comprende mejor también su dignidad de hombre, precisamente porque es el sujeto del acercamiento y de la presencia de Dios, sujeto de la condescendencia divina en la que está contenida la perspectiva e incluso la raíz misma de la glorificación definitiva. Entonces se puede repetir verdaderamente que la "gloria de Dios es el hombre viviente, pero la vida del hombre es la visión de Dios": el hombre, viviendo una vida divina, es la gloria de Dios, y el Espíritu Santo es el dispensador oculto de esta vida y de esta gloria. "El -dice Basilio el Grande- simple en su esencia y variado en sus dones... se reparte sin sufrir división... está presente en cada hombre capaz de recibirlo, como si sólo él existiera y, no obstante, distribuye a todos gracia abundante y completa"»"

La condescendencia de Dios no trivializa su trascendencia sino que en su mundanidad nos remite a ella: «Por esto también nosotros sin cesar damos gracias a Dios: cuando recibieron la palabra de Dios que oyeron de nosotros, la aceptaron no como la palabra de hombres, sino como lo que

\footnotetext{
9 Tomás de Aquino, Summa Theologiae II-II, q. 1, a. 2, ad 2 [Texto extraído del Catecismo de la Iglesia Católica, 170).

10 Juan Crisóstomo, Homilía 11 (citado por J.Quasten, Patrología, v.II, BAC, Madrid 1994, 488).

11 Juan Pablo II, Dominum et vivificantem, 59.
} 
realmente es, la palabra de Dios, la cual también hace su obra en ustedes los que creen» (1 Tes 2,13).

De este modo, la idea de condescendencia de Dios nos ayuda así a comprender que toda enseñanza teológica debe acontecer «sin mengua de la verdad y de la santidad de Dios». Ésta es una cuestión sobre la que hizo especial hincapié Juan Pablo II, en su Encíclica Fides et ratio. Justamente hablando de las consecuencias que para la teología tienen los hechos de la kénosis y de la condescendencia, el Papa afirma la necesidad que ella no se quede en el «dato positivo» de los testimonios de la Revelación (Escritura y Tradición viva de la Iglesia) sino que descubra en ellos el sentido y significado al cual remiten ${ }^{12}$. Sería equivocado comprender nuestra labor pedagógica sólo como inducción a datos positivos que se validan autónomamente, sin ninguna referencia ya a la «verdad y santidad de Dios». El lenguaje humano, en este caso, deja de ser expresión histórica del acontecimiento de la autocomunicación de Dios, y se constituye en un mero «objeto» de la voluntad de poder del hombre. En clave de condescendencia, el desafío pedagógico consiste, justamente, en llegar a admirar esta condescendencia que nace del amor y de la libertad de Dios y que se expresa en la trama de nuestra historia, en las texturas y pliegues de nuestros lenguajes.

Como explica el papa Benedicto, «el Dios creador es también el Dios de la condescendencia (synkatabasis). Nosotros somos débiles para "ascender", nuestros ojos son débiles. Así, Dios se convierte en el Dios de la condescendencia, que envía al hombre, caído y extranjero, una carta, la sagrada Escritura. De este modo, la creación y la Escritura se completan. A la luz de la Escritura, de la carta que Dios nos ha dado, podemos descifrar la creación. Juan Crisóstomo llama "Padre tierno" (philostorgios) (ib.), médico de las almas (Homilía 40, 3 sobre el Génesis), madre (ib.) y amigo afectuoso (Juan Crisóstomo, Sobre la Providencia 8,11-12). Pero a este segundo paso -el primero era la creación como "escalera" hacia Dios; y el segundo, la condescendencia de Dios a través de la carta que nos ha dado, la sagrada Escritura - se añade un tercer paso: Dios no sólo nos transmite una carta; en definitiva, él mismo baja, se encarna, se hace realmente "Dios con nosotros", nuestro hermano hasta la muerte en la cruz» ${ }^{13}$.

\footnotetext{
12 Cf. Juan Pablo II, Fides et Ratio, 93 y ss.

13 Benedicto XVI, Audiencia General, 26 de Septiembre de 2007.
} 


\section{La enseñanza teológica al servicio de la inteligencia de lo que hemos visto y oído}

Cuando destacamos la condescendencia divina como autocomunicación de Dios en Cristo y como proceso dialógico no estamos negando la existencia de una enseñanza o doctrina asociada intrínsecamente a estos procesos comunicativos. La relación del hombre con Dios no acontece en los solos afectos o sentidos. Dios no apela a una entrega ciega, sino que a un asentimiento libre e inteligente a aquello que Él nos ha revelado [cf. DH 3010]. Toda enseñanza teo-lógica no puede sino enraizarse en este propósito fundamental de contribuir a una inteligencia creativa de aquello que Dios nos ha querido manifestar en los hechos y palabras de su Hijo Jesús.

Según la DV 2 «lo que» Dios revela es a sí mismo y el misterio de su voluntad. Por cierto, el carácter personal es decisivo, pero es inseparable de aquello que constituye su voluntad para nosotros. Así lo expresó Jesús dramáticamente en el huerto cuando se dirigió a su Padre diciendo: «Abba, Padre! Para ti todas las cosas son posibles; aparta de mí esta copa, pero no sea lo que yo quiero, sino lo que tú quieras $\left[\dot{\alpha} \lambda \lambda^{\circ}\right.$ oủ $\tau \dot{~} \dot{\varepsilon} \gamma \hat{\omega}$

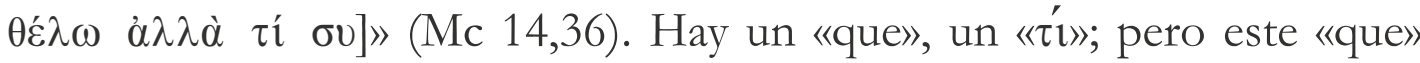
remite a palabras intrínsecamente unidas hechos. Como afirma el mismo Vaticano II: «Este plan de la revelación se realiza con palabras y hechos intrínsecamente conexos entre sí, de modo que las obras realizadas por Dios en la historia de la salvación manifiestan y confirman la doctrina y los hechos significados por las palabras, y las palabras, por su parte, proclaman las obras y esclarecen el misterio contenido en ellas» ${ }^{14}$. El problema es cuando nuestra enseñanza teológica divide, separa, atomiza..., cuando ya no se aprecia esta unidad dinámica entre hechos y palabras que enseñó el Vaticano II.

En rigor, el contenido del Evangelio no es un «algo», sino que remite a un acontecimiento vivido, a aquello que -como los pastores en Belén- ha sido oído y visto [ $\pi \hat{\sigma} \sigma v v$ oî́ de si Jesús es verdaderamente el Mesías prometido, el mismo Señor y Maestro no responde con una serie de especulaciones, o de argumento probatorios, sino que remite también a lo que todos han visto y oído:

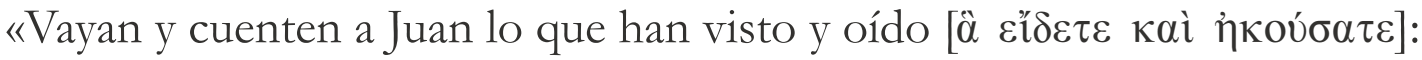
los ciegos reciben la vista, los cojos andan, los leprosos quedan limpios y los sordos oyen, los muertos son resucitados y a los pobres se les anuncia

14 Concilio Vaticano II, Dei Verbum, n.2. 
el Evangelio» (Lc 7,22; cf. Mt 11,4: «Vayan y cuenten a Juan lo que oyen y

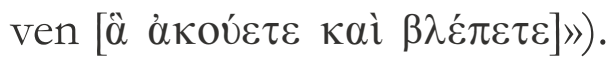

El contenido, la doctrina, las enseñanzas de Jesús nos remiten por tanto a un acontecimiento: a la irrupción del reinado de Dios en medio nuestro (cf. Lc 4, 16-21). No se trata, simplemente, de algo que ha sucedido; más bien, se trata de algo que está aconteciendo y cuyo sentido más hondo se encuentra tanto en el pasado como en el futuro: en el pasado, como cumplimiento de las promesas que Dios había hecho a su Pueblo y, en el futuro, como el horizonte de plenitud al que es conducido todo cuanto ha sido creado. En el acontecer actual del reinado de Dios, el pasado y el futuro dejan de ser unidades métricas autosustentadas y pasan a ser dinámicas temporales presentes. La condescendencia de Dios alcanza también

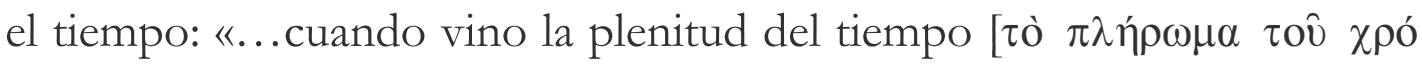
vov], Dios envió a Su Hijo, nacido de mujer, nacido bajo la Ley...» (Gal 4,4). Juan nos recuerda una y otra vez que el Espíritu quiere hablar a las iglesias, que el Espíritu tiene «algo» que decir a las Iglesias: «El que tiene

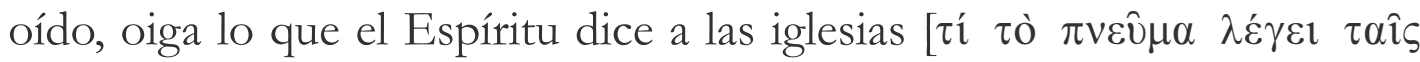
$\varepsilon \kappa \kappa \lambda \eta \sigma i ́ \alpha 1 \varsigma] \gg$ (Ap 2,7.11.17.29; 3,6.13.22). Por medio del Espíritu Santo, el acontecer del reino no es un hecho del pasado, sino que se actualiza en cada tiempo, interpelando siempre de nuevo a la comunidad de cuantos han creído en los hechos y palabras de Jesús.

Sabemos que aquello el Señor ha dicho, «lo que» se nos ha anunciado, «lo que hemos visto y oído», todo ello requiere ser comprendido, exige nuestra intelección, a fin de efectivamente pueda dar fruto en nosotros. Ésto es -recordémoslo- lo que nos enseña Jesús en la parábola del Sembrador: «A todo el que oye la palabra del reino y no la entiende, el maligno viene y arrebata lo que fue sembrado en su corazón. Este es aquél en quien se sembró la semilla junto al camino» (Mt 13,19). No sólo hay que escuchar «lo que» Jesús tiene para decirnos, sino que también debemos entenderlo: «Llamando de nuevo a la multitud, Jesús les decía: "Escuchen todos lo

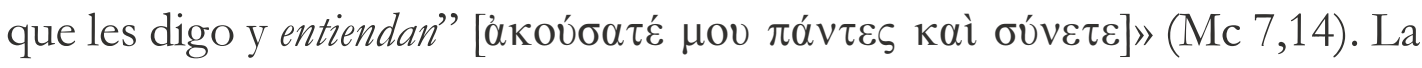
enseñanza teológica se orienta al servicio de esa comprensión de la Palabra, una comprensión que -en clave de condescendencia- acontece siempre según las condiciones y posibilidades concretas de quienes participan de los procesos de enseñanza y aprendizaje.

Será muy distinto comprender la enseñanza de la teología como la reiteración indistinta de contenidos transmitidos linealmente en el tiempo, 
que hacerlo en la perspectiva de una contribución a la inteligencia de un acontecer del reino que es siempre actual y, que, en último término, nos remite a la inteligencia del misterio mismo de Dios. En la perspectiva del cuarto Evangelio, el acontecimiento del reino nos conduce a la vida misma de Dios: «Lo que Él ha visto y oído, de eso da testimonio» [ô

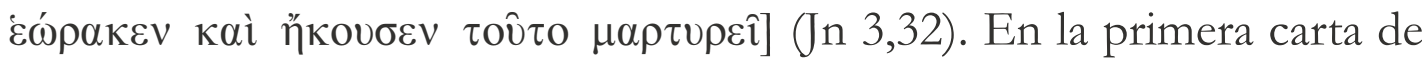
Juan se explicita cómo en aquello que «hemos visto y oído» se verifica una estrecha relación entre acontecer del reino, comunión trinitaria y comunión eclesial: «Lo que hemos visto y oído les proclamamos también a ustedes, para que también ustedes tengan comunión con nosotros. En verdad nuestra comunión es con el Padre y con Su Hijo Jesucristo» (1 Jn 1,3) (cf. Hech 4, 20.22,15).

La enseñanza teológica no puede versar sobre cualquier cosa. $\mathrm{O}$, más bien, sí puede versar sobre cualquier cosa, siempre y cuando esta «cosa» sea vista bajo el respecto del acontecer del reino, de la comunión con Dios y de la comunión de todo el género humano. Efectivamente, la admirable condescendencia del Verbo de Dios alcanza todo lenguaje humano. Pero, como se ha dicho, para que este lenguaje humano ya no sea más causa de confusión (cf. Gén 11,9), sino que expresión del acontecer siempre actual de la salvación de Dios en Cristo. La enseñanza de la teología, por tanto, deberá contribuir a que todo lenguaje humano encuentre en Cristo su plenitud. Esto supone, por cierto, una reflexión crítica, capaz de discernir entre lo que muchas veces no son más que palabras vacías y lo que, realmente, nos acerca a una comprensión inteligente de aquello que hemos «visto y oído». De allí la advertencia del Apóstol: «Timoteo,

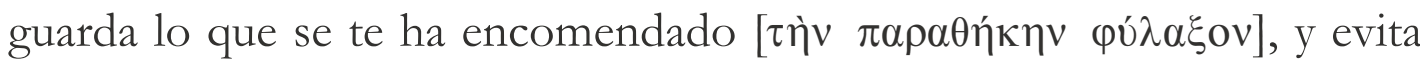
las palabrerías vacías y profanas, y las objeciones de lo que falsamente se llama ciencia, la cual profesándola algunos, se han desviado de la fe» (1 Tim 6, 20-21).

En el sentido anterior es que hay que entender el mandato apostólico

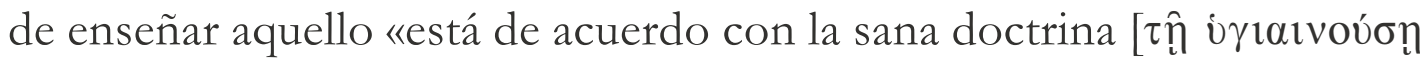
$\left.\delta 1 \delta \alpha \sigma \kappa \alpha \lambda i \alpha_{1}\right] »($ Tit 2,1). ¿Y qué es la «sana doctrina»? La misma Carta a Tito lo explicita: «Los ancianos deben ser sobrios, dignos, prudentes, sanos en la fe, en el amor, en la perseverancia. Asimismo, las ancianas deben ser reverentes en su conducta, no calumniadoras ni esclavas de mucho vino. Que enseñen lo bueno... » (Tit 2,2-3). La «sana doctrina» no tiene que ver con un conjunto de alambicadas verdades, sino con el acontecer del reino, con aquello que hemos visto y oído, en último 
término, con aquellos dos mandamientos de los que «dependen toda la Ley y los Profetas» (Mt 22,40): «Amarás al Señor tu Dios con todo tu corazón, y con toda tu alma, y con toda tu mente.... Amarás a tu prójimo como a ti mismo» (Mt 22,37.39; cf. Mc 12,28-31; Lc 10,25-28). En la Carta a Tito, inmediatamente antes de utilizarse el concepto de «sana doctrina», se nos da la clave para comprender cuál es su opuesto, cuál es la situación que niega aquello que hemos visto y oído, que representa nuestra enfermedad mortal; ésta no es la «falsa doctrina», sino el profesar conocer a Dios y, sin embargo, negarlo con nuestros hechos (cf. Tit 1,16; cf. Rom 7,19).

En el Evangelio según Mateo nos encontramos con un breve pasaje en el que Jesús, en un contexto de polémica con los fariseos, invita a los éstos a un significativo aprendizaje: «...vayan, y aprendan lo que significa: "misericordia quiero y no sacrificio"; porque no he venido a llamar a justos, sino a pecadores» (Mt 9,13). Este texto me parece particularmente importante, por cuanto Jesús asocia el aprendizaje de «lo que es misericordia» al ir a aprender. Se trata de un movimiento, de un aprendizaje que se hace en una práctica. Por ello, el mismo Mateo nos explica el profundo nexo que existe entre teoría y práctica, entre saber y actuar. Una mala práctica -a menudo- está fundada en una falsa comprensión: «...si ustedes hubieran sabido lo que esto significa: "misericordia quiero y no sacrificio" no hubieran condenado a los inocentes» (Mt 12,7).

Ésa es la inteligencia que se requiere alcanzar en la teología, en su proceso de enseñanza y de aprendizaje. Cualquier otra cosa es tangencial y mostrará su valor, tanto cuanto contribuya a entender el nexo profundo que Jesús enseñó entre profesión-confesión de fe y práctica a favor del prójimo: «No todo el que me dice: «Señor, Señor», entrará en el reino de los cielos, sino el que hace la voluntad de mi Padre que está en los cielos» (Mt 7,21). La enseñanza teológica debe ser sólida y nos debe ayudar a construir nuestra existencia personal y social sobre roca (cf $\mathrm{Mt}$ 7,24). Pero esto, en clave de condescendencia, no es aferrarse a fórmulas doctrinales esclerotizadas, sino hacerse discípulos de quien «siendo rico se hizo pobre» (2 Cor 8,9$)$, de quien nos mostró el amor sorprendente de Dios (Rom 5,8), de quien amándonos hasta el extremo nos invita a $\operatorname{amar}(1 \mathrm{Jn} 4,11)$. 


\section{La enseñanza teológica es interpelación a la libertad}

Por último, la categoría de condescendencia de Dios nos ofrece una perspectiva teológica fundamental para nuestra enseñanza por cuanto ella nos remite a un acontecimiento de libertad. Cómo decíamos, para San Pablo la misma kénosis de Cristo es una interpelación a la libertad, un llamado

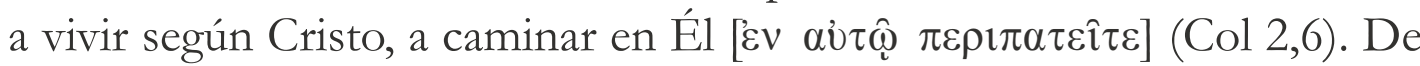
este modo, la enseñanza teológica no se debiera limitar a la transmisión de un conjunto de enseñanzas y de verdades, sino que debe ser capaz de mostrar el carácter provocativo que éstas tienen para la inteligencia del hombre, para la comprensión de sí mismo y de su ser en el mundo.

Pablo escribía así a los Corintios: «Porque si la trompeta da un sonido incierto, ¿quién se preparará para la batalla? Así también ustedes, a menos de que con la boca pronuncien palabras inteligibles, ¿cómo se sabrá lo que dicen? Pues hablarán al aire» (1 Cor 14, 8-9). De allí que, en esta misma carta, Pablo declare que prefiere «cinco palabras con sentido» que «diez mil en lenguas» (1 Cor 14,19). La cuestión no está sólo, ni principalmente, en la espectacularidad de los conceptos, en la belleza del lenguaje, en la lógica de los argumentos. Todo ello se requiere en la enseñanza de la teología, pero no es suficiente; se exige, además, que todo ello remita al sentido, al significado, a la inteligencia. Probablemente, más de una vez hemos hecho aquella experiencia de «hablar al aire», como lo expresa Pablo. Siguiendo su consejo, en lugar de echarle la culpa a nuestros estudiantes, debiéramos preguntarnos por la «inteligibilidad» de nuestras palabras, afirmaciones, escritos. Y, por cierto, la inteligibilidad de la que se trata nace de la misma idea de condescendencia divina; es decir, no es una inteligibilidad abstracta, autorreferida, satisfecha de sí misma; más bien, se trata de una inteligibilidad de carácter comunicativo, de una efectiva interpelación a la libertad. Una enseñanza teológica que no sea interpelación a la libertad, difícilmente será reconocible como una enseñanza sustentada en quien nos liberó para la libertad (cf. Gal 5,1).

Con todo, la condescendencia divina -como interpelación a la libertadpareciera que no asegura ningún éxito pedagógico. Los testimonios neotestamentarios nos relatan múltiples obstáculos en el aprendizaje que van haciendo los discípulos de Jesús. Por ejemplo, en Marcos 9,32 se nos cuenta que «ellos no entendían lo que les decía, y tenían miedo de preguntar a Jesús» (cf. Lc 2,50; 9,45; 18,34; Jn 8,27; 10,6; 12,16; Hech $22,9)$. Como expresaba el Papa Juan Pablo II: «Por desgracia, a través de 
la historia de la salvación resulta que la cercanía y presencia de Dios en el hombre y en el mundo, aquella admirable condescendencia del Espiritu, encuentra resistencia y oposición en nuestra realidad humana» ${ }^{15}$. Esta condescendencia del Espiritu es la que el mismo Jesús había prometido a sus discípulos: «... el Espíritu de verdad, a quien el mundo no puede recibir, porque ni lo ve ni lo conoce, pero ustedes sí lo conocen porque mora con ustedes y estará en ustedes». Será el Espíritu Santo, quien habitando para siempre en nosotros, nos conducirá a la verdad completa.

Justamente, como interpelación a la libertad, la enseñanza teológica también se puede topar con la incomprensión. Ya no con aquella incomprensión que puede resultar de deficiencias en el proceso de enseñanza y aprendizaje, sino con aquella que es producto de una negativa a acoger y dejarse transformar por el Espíritu de Dios.

Como certeramente lo expresara Juan Pablo II, pertenece al hecho mismo de la condescendencia de Dios el quedar referida a la libertad del hombre: «La Palabra no da fruto automáticamente: aunque es divina, y por tanto omnipotente, se adapta a las condiciones del terreno, o mejor aún, acepta las respuestas que le da el terreno, y que pueden ser también negativas. Misterio de la condescendencia de Dios, que llega incluso a ponerse completamente en manos de los hombres. Porque, en el fondo, la semilla sembrada en los diversos terrenos es Jesús mismo (cf. Jn 12, 24)» ${ }^{16}$.

Más explícitamente, Lucas formula el sentido pneumatológico que posibilita el ejercicio de la libertad: «Cuando los lleven a las sinagogas y ante los gobernantes y las autoridades, no se preocupen de cómo o de qué hablarán en defensa propia, o qué van a decir; porque el Espíritu Santo en esa misma hora les enseñará lo que deben decir» (Lc 12,11-12). Por la gracia del Espíritu no sólo llegaremos a una comprensión mayor del misterio mismo de Dios, sino que también se abrirán nuevas posibilidades para dar un testimonio creíble de Jesús como el Cristo, especialmente en circunstancias de persecución y de muerte: «... cuando los entreguen, no se preocupen de cómo o qué hablarán; porque a esa hora se les dará lo que habrán de hablar» (Mt 10,19).

15 Juan Pablo II, Dominum et vivificantem. Sobre el Espíritu Santo en la vida de la Iglesia y del mundo [18 de mayo de 1986], 55.

16 Juan Pablo II, Homilía en viaje apostólico a Eslovaquia [13 de septiembre de 2003]. 
Pero, como interpelación a la libertad, el mismo proceso de enseñanza y aprendizaje queda determinado escatológicamente. No lo sabemos ni comprendemos todo: «Amados, ahora somos hijos de Dios y aún no se ha manifestado lo que habremos de ser. Pero sabemos que cuando Cristo se manifieste, seremos semejantes a Él, porque lo veremos como Él es» (1 Jn 3,2). La enseñanza teológica no debe apresurar mañosamente el ésjaton de Dios. Por el contrario, resistiendo toda tentación inmediatista, la enseñanza teológica debe siempre abrir a la comprensión de un Dios que es siempre mayor, debe animar la esperanza de quienes decimos «Ven, Señor Jesús» (Ap 22,20), debe sostener «el anhelo profundo de la creación que aguarda ansiosamente la revelación de los hijos de Dios» (Rom 8,19).

\section{Reflexiones finales}

Porque la condescendencia de Dios nos remite al acontecimiento de la salvación, entonces la teología no se queda en la mera contemplación de Dios, sino que ella busca escudriñar el misterio del Verbo encarnado; es decir, la teología se pregunta por el sentido histórico-salvífico al que remiten los hechos y palabras de Jesús, por las condiciones y posibilidades del ser humano para comprender y acoger dicho acontecimiento, por las consecuencias que tiene para su existencia personal y social el dejarse transformar por la acción del Espíritu.

En el primero de todos los artículos de la Suma Teológica pregunta Santo Tomás lo siguiente: «¿Es o no necesario que, además de la materias filosóficas, haya otra doctrina?». En su respuesta, por cierto, Tomás afirma la necesidad de una «ciencia cuyo criterio fuera la revelación divina». Pero, lo interesante en su respuesta es la razón que da para tal afirmación: esta ciencia es necesaria para la salvación bumana [fuit necessarium bumanam ad salutem $]^{17}$. En esta perspectiva, la idea de condescendencia justamente nos ha ayudado a comprender que si la enseña teológica no se orienta a la salvación humana, entonces, ella no sirve de nada. Esto, por cierto, no basta declararlo. Tanto maestros como discípulos deben poder experimentar que, realmente, la teología contribuye a la experiencia histórico-escatológica de la salvación.

Por ello, Bernhard Welte destaca y adhiere a la formulación del Maestro Eckhart, según la cual «un Maestro de vida (Lebemeister) vale más que

\footnotetext{
Tomás de Aquino, STh I, q 1, a. 1.
} 
miles de Maestros de cátedra (Lesemeister) $\rangle^{18}$. Efectivamente, de lo que se trata es de la vida, de la vida en plenitud: «He venido para que tengan vida, y para que la tengan en plenitud» (Jn 10,10), dice Jesús. Si la enseñanza de la teología no se ordena a esta vida plena en Cristo, entonces no será ni auténtica enseñanza, ni auténtica teología. Ciertamente, ser Lebemeister nos compromete existencialmente con aquello que enseñamos, nos obliga a reconocer al otro en lo que realmente es, busca y anhela; nos impulsa a un auténtico diálogo con los demás; nos invita a reconocer al otro también como sujeto de la teología. El concepto de condescendencia nos ha ayudado a comprender mejor qué implica la enseñanza teológica para quienes hemos sido llamados a ser Lebemeister.

No hemos querido sobre significar el concepto de condescendencia; pero, como categoría teológica fundamental, él nos ha permitido reconocer cómo en el Logos de Dios se funda la posibilidad de nuestro lenguaje sobre Él y, más en particular, cómo la enseñanza de la teología puede contribuir a hacer inteligible el amor y el misterio de Dios, el acontecer del reino, el llamado a la libertad de la Palabra que se hizo carne y puso su morada entre nosotros.

18 Cf. B. WeLte, Meister Eckhart, 16. 
Resumen: los procesos de enseñanza y aprendizaje teológicos exigen de profesores y estudiantes capacidades pedagógicas que no sólo sean coherentes con los hallazgos de las ciencias de la educación, sino que además sean consecuentes con el objeto que se estudia: la revelación de Dios en Cristo y los testimonios de su interpretación y transmisión en la historia. Por ello el autor propone el concepto de condescendencia divina como clave teológica fundamental para impulsar procesos pedagógicos que sean consistentes, tanto pedagógica como teológicamente. El concepto de condescendencia, empleado magistralmente en el Concilio Vaticano II, es analizado principalmente de acuerdo a sus antecedentes bíblicos y patrísticos y, así, se descubre la capacidad que él tiene para descubrir cómo en el Logos de Dios se funda la posibilidad de nuestro lenguaje sobre Él, cómo en la dinámica de la condescendencia la enseñanza de la teología se hace expresión del amor de Dios, nos remite a su cercanía siempre trascendente, nos ayuda a una inteligencia siempre actual de «lo que hemos visto y oído» y, finalmente, cómo la enseñanza de la teología sólo se puede validar como interpelación a la libertad.

Palabras clave: pedagogía teológica, revelación, condescendencia.

Abstract. The processes of theological teaching and learning demand pedagogical abilities of teachers and students which are not only consistent with findings in education sciences, but also with the object of study: the revelation of God in Christ and the testimonies of its interpretation and transmission through history. Based on this, the author proposes the concept of Divine Condescension as a fundamental theological key to promote pedagogical processes that are both educationally and theologically consistent. The concept of condescension, which is employed masterfully in the Second Vatican Council, is principally analyzed according to its biblical and patristic background, thus uncovering its capacity to discover how the possibility of our language about him is founded in the Logos of God; how teaching theology through the dynamics of condescension becomes an expression of the love of God, shows us his ever transcendent proximity, and guides us to an ever present intelligence of «what we have seen and heard»; and finally how teaching theology can only be validated as questioning liberty.

Key words: Theological pedagogy, revelation, condescension. 